\title{
Chinese ecosystem research network: Progress and perspectives
}

\author{
Bojie $\mathrm{Fu}^{\mathrm{a}, \mathrm{d}, *}$, Shenggong Li ${ }^{\mathrm{b}, \mathrm{d}}$, Xiubo Yu ${ }^{\mathrm{b}, \mathrm{d}}$, Ping Yang ${ }^{\mathrm{c}, \mathrm{d}}$, Guirui Yu ${ }^{\mathrm{b}, \mathrm{d}}$, \\ Renguo Feng ${ }^{\mathrm{c}, \mathrm{d}}$, Xuliang Zhuang ${ }^{\mathrm{c}, \mathrm{d}, * *}$ \\ ${ }^{a}$ State Key Laboratory of Urban and Regional Ecology, Research Center for Eco-Environmental Sciences, Chinese Academy of Sciences, Beijing 100085, China \\ ${ }^{\mathrm{b}}$ Institute of Geographic Science and Natural Resources Research, Chinese Academy of Sciences, Beijing 100101, China \\ ${ }^{\mathrm{c}}$ Bureau of Science and Technology for Resources and Environment, Chinese Academy of Sciences, Beijing 100864, China \\ ${ }^{\mathrm{d}}$ Chinese Ecosystem Research Network, Chinese Academy of Sciences, Beijing, China
}

\section{A R T I C L E I N F O}

\section{Article history:}

Received 3 April 2009

Received in revised form 5 February 2010

Accepted 10 February 2010

Available online 6 March 2010

\section{Keywords:}

Long-term ecological research

Chinese ecosystem

Progress and accomplishments

Planning and perspectives

\begin{abstract}
A B S T R A C T
As a national innovative scientific and technological facility that integrates monitoring, research and demonstrations, the Chinese Ecosystem Research Network (CERN) has become one of the largest networks in the world that consists of 40 field stations, 5 sub-centers and 1 synthesis center, covering almost all typical ecosystems in China: cropland, forest, grassland, desert, marshes, lakes, bays and urban ecosystem. Its unique features are the emphasis on understanding long-term structure and function, patterns and processes of ecosystems, combination of the inter-site comprehensive research or crosssite comparison research and the voluntary site-based exploration, and the data sharing both for domestic institutions and international networks at different levels. This paper provides a brief review of CERN by introducing its developing history, objectives and missions, summarizing its progress with the long-term ecological research in China including monitoring, scientific accomplishments in carbon cycle, ecosystem structure and functions, ecosystem restoration and data management. The paper also describes CERN's strategic plan to 2020 and its development perspectives in the future with focus on six core thematic areas.
\end{abstract}

(c) 2010 Elsevier B.V. All rights reserved.

\section{Introduction}

Chinese Ecosystem Research Network (CERN) was established in 1988. Over the past 20 years, as one of major component of Global Terrestrial Observing System (GTOS) and International Long-Term Ecological Research (ILTER), CERN has grown to be an important research platform for the sites and partners both at home and abroad, which owe greatly to the data measured and collected on long-term and continuous basis, and also the up-todate facilities and instruments in the field stations that represent the major ecosystem types in China.

Up to now, CERN has been developed into an innovative scientific and technological facility that integrates monitoring, research and demonstrations. It has become one of the largest national networks that consist of 40 field stations (Fig. 1), 5 subcenters and 1 synthesis center, with over 2000 scientists,

\footnotetext{
* Corresponding author at: State Key Laboratory of Urban and Regional Ecology, Research Center for Eco-Environmental Sciences, Chinese Academy of Sciences, Beijing 100085, China. Tel.: +86 1062923557 ; fax: +861062923557.

** Corresponding author at: Bureau of Science and Technology for Resources and Environment, Chinese Academy of Sciences, Beijing 100864, China. Tel.: +8610 68597540; fax: +861068597583.

E-mail addresses: bfu@rcees.ac.cn (B. Fu), xlzhuang@cashq.ac.cn (X. Zhuang).
}

technicians and graduate students engaged in its activities. By providing long-term scientific data, they have played a critical role in helping the nation address such issues as ecology development, environmental protection, agriculture, disasters reduction and natural resources management.

\section{Objectives and missions of CERN}

The main objectives of CERN are in the following three aspects: to obtain scientific data of ecosystem change by using multiplication approaches such as long-term dynamic monitoring, ecological experiments, remote sensing and modeling; to study the changes in structure, functions and processes of different ecosystems driven by global changes and human activities; to provide technique and scientific suggestions to decision-makers for national ecosystem management, agricultural production and ecological remediation.

The central, literal aim of CERN is to understand long-term changes in ecosystem pattern, processes and services and the underlying mechanisms under the conditions of natural environmental changes and human activities. While each site has its own scientific problem and specific regional characters, all sites are required to perform the following four common research areas to ensure cross-site and network-level comparisons: biotic communities composition, structure, biodiversity; ecosystem 


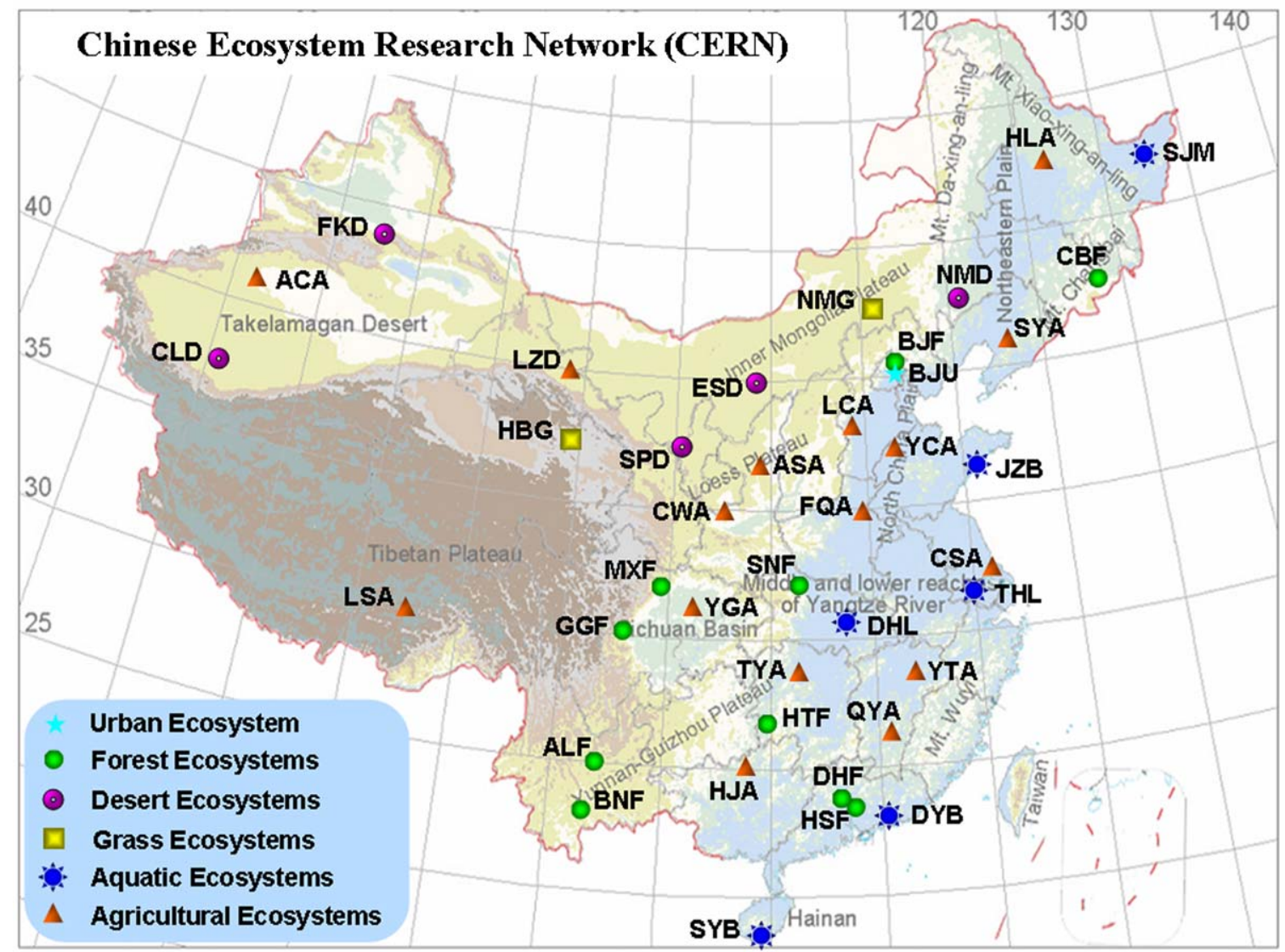

Fig. 1. Field station distribution map of CERN.

\begin{tabular}{|c|c|c|c|c|c|}
\hline \multicolumn{2}{|c|}{ Agricultural ecosystems: 15} & \multicolumn{2}{|c|}{ Forest ecosystems: 10} & \multicolumn{2}{|c|}{ Aquatic ecosystems: 6} \\
\hline ACA & Akesu & $\mathrm{BJF}$ & Beijing F & Marsh & 1 \\
\hline LSA & Lasa & MXF & Maoxian & SJM & Sanjiang \\
\hline HLA & Hailun & GGF & Gonggashan & Lake & 2 \\
\hline YCA & Yucheng & ALF & Ailaoshan & DHL & Donghu \\
\hline ASA & Ansai & BNF & Banna & THL & Taihu \\
\hline CWA & Changwu & HSF & Heshan & Bay & 3 \\
\hline YTA & Yingtan & DHF & Dinghushan & $\mathrm{JZB}$ & Jiaozhouwan \\
\hline CSA & Changshu & SNF & Shennongjia & SYB & Sanya \\
\hline TYA & Taoyuan & HTF & Huitong & DYB & Dayawan \\
\hline FQA & Fengqiu & CBF & Changbaishan & & \\
\hline YGA & Yanting & & & & \\
\hline LCA & Luancheng & & & & \\
\hline HJA & Huanjiang & & & & \\
\hline QYA & Qianyanzhou & & & & \\
\hline SYA & Shenyang & & & & \\
\hline \multicolumn{2}{|c|}{ Desert ecosystems: 6} & \multicolumn{2}{|c|}{ Grass ecosystems: 2} & \multicolumn{2}{|c|}{ Urban ecosystem: 1} \\
\hline CLD & Cele & HBG & Haibei & BJU & Beijing U \\
\hline ESD & Erdos & NMG & Neimenggu & & \\
\hline FKD & Fukang & & & & \\
\hline LZD & Linze & & & & \\
\hline NMD & Naiman & & & & \\
\hline SPD & Shapotou & & & & \\
\hline
\end{tabular}

productivity, energy flow and materials cycles; human-environment-ecosystem interactions; ecosystem management and acclimation to global changes. To achieve this aim, the missions of CERN are implemented by following ways: (i) ecological monitoring: to continuously measure and record changes in ecosystem structure, processes, and function, (ii) ecological research: to understand ecosystem dynamics and the underlying mechanisms, in response to environmental changes and human perturbation, (iii) ecological application: to explore and demonstrate ecological techniques and options to enhance and sustain ecosystem services, (iv) consultation: to provide consulting suggestions to resource managers, and policy makers to address complex environmental challenges, on the basis of synthesis of information gained from long-term research and development of theory and technological application, and (v) public education: to store and disseminate well assimilated, normalized database and knowledge with regard to ecological 
status, trends and new discoveries to the broader ecological community and general public.

\section{Progress of long-term ecological research in China}

\subsection{Monitoring}

Long-term monitoring of changes in ecosystem components is indispensable in identifying and tackling the environmental issues. One of the core missions of CERN is to implement long-term ecological monitoring on the biological and environmental elements of the major terrestrial and aquatic ecosystems in China, i.e. cropland, forest, grassland, desert, marshes, lakes, and bays, etc. on the basis on the 40 CERN field stations, and further to provide updated information on the state of major ecosystems for scientific research. Moreover, the important ecological processes, such as the ecosystem energy and matter flows (e.g. carbon cycle, water budget, nitrogen exchange and balance) are also measured at some stations to meet the specific requirements of different research programs of government institutions. Long-term monitoring at CERN stations provides not only information on ecological and environmental changes in regional and national scales, but also a platform for application and development of new ecological technologies and approaches, validation of ecological models by linking surface-based measurements and estimates from remote sensing. At present, the major ecological monitoring tasks based on CERN stations are as follows.

\subsubsection{The routine long-term ecological and environmental monitoring}

All the field stations of CERN continuously measure and record the temporal variations in hydrological, pedological, atmospheric and biological elements of major terrestrial and aquatic ecosystems in China. The meteorological and atmospheric environments (such as solar radiation, ultraviolet radiation, photosynthetic active radiation, net radiation, surface reflected radiation, soil heat flux, soil temperature profile, wind direction, wind speed, air temperature, air humidity, precipitation and pan evaporation), soil physical and chemical properties, vegetation structure and function (such as plant species composition, leaf area index, and biomass), water budget (such as precipitation, evaporation, transpiration, and runoff), and nutrient budget (N, P, K) are periodically recorded at some of the CERN stations according to the standard monitoring protocols. Most stations initially implemented such routine long-term ecological and environmental monitoring from 1988 and have acquired the data over 20 years. The high quality datasets collected on the long-term and continuous basis provide foundation for the ecological research. For example, observation at CERN field stations shows that ultraviolet radiation in China increases longitudinally from east to west, and increases latitudinally from north to south in the west and from south to north in the east (Hu et al., 2007a). Similar pattern for photosynthetically active radiation (PAR) was observed ( $\mathrm{Hu}$ et al., 2007b). There is a distinct seasonality of the ratio of PAR to solar radiation, which is lower in autumn and winter seasons when rainfall or relative humidity is low, and higher in summer (Hu et al., 2007b). Based on the observation of 19 ecological field stations and 4 city stations of the CERN since 2003, there is also a clear seasonality of atmospheric aerosol optical depth (AOD) which is higher in summer and lower in autumn and winter and receiving strong influences from spring dust storms in the north and pollution of biofuel and fossil fuel combustion in autumn and winter (Xin et al., 2007). Nutrient cycle experiments, especially nitrogen cycle experiments conducted at the CERN research stations of forest, grassland, cropland, and desert ecosystems highlight the nutrient status and dynamics.

\subsubsection{Terrestrial ecosystem flux observation}

In 2002, Chinese Terrestrial Ecosystem Flux Observational Research Network (ChinaFLUX) was established based on some field stations of CERN. ChinaFLUX applies the eddy covariance technique and the chamber method to continuously measure the exchanges of $\mathrm{CO}_{2}$, water vapor and energy between terrestrial ecosystem and the atmosphere across diurnal, daily, seasonal and interannual time scales over typical forest, grassland and cropland ecosystems in China (Yu et al., 2006c). Since its establishment, ChinaFLUX has developed rapidly and expanded from the initial 8 sites into a national scale network with observation sites covering most of the terrestrial ecosystem types in China. The continuous network-based observation on $\mathrm{CO}_{2}, \mathrm{H}_{2} \mathrm{O}$ and energy fluxes over diverse ecosystems has provided a valuable datasets for synthetic research on eco-hydrological processes at ecosystem and regional scales and make it possible to estimate and predict spatiotemporal variabilities of carbon and water cycles under global climate change scenario.

\subsubsection{Terrestrial transects investigation}

In China, the NorthEast Chinese Transect (NECT) and NorthSouth Transect of Eastern China (NSTEC) were accepted by IGBP/ GCTE as the fifth and fifteen international transect in 1993 and 1999 respectively. NECT and NSTEC are mainly driven by moisture and temperature respectively. Four field surveys and samplings along NECT were conducted in 1995, 1997, 1999 and 2001 respectively. These surveys were conducted over 107 sites across forests and grasslands in northeast China. In addition, two extensive surveys were carried out along NSTEC in 2006 and 2007 respectively. NSTEC survey covered all forest types in eastern China and with 125 sites established. The investigated items included vegetation type, biomass, leaf area index, plant diversity, etc. Samples of leaves, twigs and roots of representative trees, litter, and surface soils were collected to measure contents of $C, N$, $\mathrm{P}$, contents of ${ }^{13} \mathrm{C},{ }^{15} \mathrm{~N}$ and their natural abundance. Besides, similar investigation was conducted in 2005 and 2007 along Grassland China Transect (GCT), which extends from the steppe ecosystems in Inner Mongolia Plateau to the alpine meadow ecosystems in Qinhai-Tibet Plateau. A transect database is established which covers climate, meteorology, geomorphology, land use change and cover (LUCC), vegetation types, biomass, and soils at local and regional scales.

\subsubsection{Control experiment and monitoring}

In order to study the responses and acclimatization of ecosystem processes and functions to the global change, some environmentally controlled experiments have been carried out at the CERN field stations with financial supports from different government agencies. The first FACE (free-air $\mathrm{CO}_{2}$ enrichment) experiment in China was established in 2001, over a rice/wheat rotation cropland in Wuxi, Yangzhou, which aims to study the response of rice/wheat cropping system to the enrichment of atmospheric $\mathrm{CO}_{2}$. Besides, OTC (Open-Top Chamber) experiments were carried out at a temperate mixed forest at Changbai Mountain in northeastern China, a temperate semi-arid steppe in Inner Mongolia, and an alpine meadow in the Qinghai-Tibet Plateau. These experiments simulate different scenarios of future climate changes, such as climate warming, $\mathrm{CO}_{2}$ enrichment, precipitation change, and monitor and estimate the changes of ecosystem functioning in response to global change.

Many efforts have also been made to standardize the long-term monitoring techniques and data collection methods among all the CERN stations according to the ecological types of crop, forest, grass, water, desert, swamp (marsh). The guidance for long-term monitoring and data quality control has been published in the Monitoring Manual of CERN. 


\subsection{Scientific research}

As the third largest country by the total land area, China occupies approximately $6.5 \%$ of the world land area, and stretches about $5500 \mathrm{~km}$ from north to south and around $5000 \mathrm{~km}$ from east to west. China boast diverse climates and biomes with gradients or belts of disparate latitude, longitude, and altitude. There are tropical, subtropical, temperate, medium temperate and frigid temperate climate zones from the south of China to the north, and humid, semi-humid, semi-arid to arid areas from the southeast to the northwest. As the highest and biggest plateau in the world, the Tibetan Plateau, also known as the Qinghai-Tibetan Plateau is covered by a high-altitude arid steppe interspersed with mountain ranges and large brackish lakes. Since its establishment in 1988, the CERN field stations have conducted a number of studies on variations in structure and functions of typical ecosystems (forests, grasslands, croplands, waters, and wetlands) in terms of biogeochemical cycles, such as water and nutrient cycles and energy balance. Here a brief summary of research achievements in some of typical terrestrial ecosystems based on CERN is presented.

\subsubsection{Carbon cycle in China}

3.2.1.1. Carbon uptake of terrestrial ecosystem. Over past several decades, since the terrestrial ecosystems can account for over $40 \%$ of the emissions of carbon from fossil fuels and are one of most important players in reducing greenhouse effect. The interest in carbon sequestration by terrestrial ecosystems and its roles in balancing the global carbon budget have been ever increasing carbon sequestration by terrestrial ecosystems in China and play an important role in balancing and reducing national greenhouse gas emissions. Accurate quantification of the terrestrial carbon sink needs a clear understanding of the interannual variations associated with climate variability. Cao et al. (2003) used a process-based biogeochemical model and a remote sensing-based production efficiency model to estimate the variations in net primary production (NPP), soil heterotrophic respiration (HR), and net ecosystem production (NEP) caused by climate variability and atmospheric $\mathrm{CO}_{2}$ increase in China during the period 1981-2000. The results show that China's terrestrial NPP varied between 2.86 and $3.37 \mathrm{Gt} C$ per year with an annual growth rate of $0.32 \%$, and $\mathrm{HR}$ varied between 2.89 and $3.21 \mathrm{Gt} C$ per year with an annual growth rate of $0.40 \%$ in the period 1981-1998. The increases in NPP were attributed to increases in precipitation and atmospheric $\mathrm{CO}_{2}$, whereas the increases in HR were related mainly to global warming, net ecosystem production (NEP) varied between -0.32 and $0.25 \mathrm{Gt} C$ per year with a mean value of $0.07 \mathrm{Gt} C$ annually, leading to carbon accumulation of $0.79 \mathrm{Gt}$ in vegetation and $0.43 \mathrm{Gt}$ in the soils during the research period. The change in NPP contributed more to the interannual variations in NEP than the change in HR in the arid northern China but less in the moist southern China. Statistically, NEP had no significant variation because of the high uncertainty, but the mean annual NEP in the 1990s was lower than that in the 1980s as the increases in NEP in southern China were offset by the decreases in northern China. These estimates indicate that China's terrestrial ecosystems were taking up carbon but the carbon sequestration capacity was undermined by the ongoing climate change. The estimated NEP related to climate variation and atmospheric $\mathrm{CO}_{2}$ increase may account for $40-80 \%$ of variations in the total terrestrial carbon sink in China.

3.2.1.2. Carbon fluxes in terrestrial ecosystems. Based on the continuous measurements of $\mathrm{CO}_{2}$ fluxes between vegetation and the atmosphere by ChinaFLUX network, we evaluated the spatial pattern of carbon source/sink of the major terrestrial ecosystems and analyzed the effects of climatic and environmental changes on carbon fluxes during 2003-2005. Although a significant difference in net ecosystem production (NEP) existed among different years and among different forest sites along the NSTEC, the three forest ecosystems (i.e. Changbaishan temperate mixed forest (CBS), Qianyanzhou subtropical coniferous plantation (QYZ) and Dinghushan subtropical evergreen broad-leaved forest (DHS)) are acting as carbon sinks during 2003-2005 (Yu et al., 2006b). The forests at CBS and DHS are two old-growth forests. At CBS, seasonal variations of carbon fluxes (NEP and GPP) generally followed the seasonal trend of temperature, with the peak value of NEP and GPP occurring in June. At QYZ, ecosystem carbon fluxes showed similar seasonal trend to air temperature, except for an apparent decrease suffering from the summer drought abound July and August. At DHS, ecosystem respiration (RE) attained the highest values in July following the trend similar to air temperature; however, GEP was largest in October with higher radiation and less fog during the dry season (Yu et al., 2008).

The flux measurements show that the semi-arid steppe in Inner Mongolia was loosing carbon during 2003-2005, with the distinct seasonal and interannual variations as a result of the large fluctuation in precipitation. The decrease in annual precipitation may obviously constrain the carbon uptake in the semi-arid ecosystem in China (Fu et al., 2006). In contrast to the temperate steppe, the alpine meadow and alpine shrub-meadow at Haibei in northeastern Tibet Plateau were net carbon sinks during the observed periods. However, the net annual carbon budget of alpine swamp meadow at Haibei seems to be a carbon source, possibly due to its rich soil organic matter and larger soil respiration during the long dormant season (Zhao et al., 2005). The alpine steppemeadow at Dangxiong, located at the south edge of the Tibet Plateau, is carbon neutral with slight shift between small carbon sink and source in response to the variation in precipitation (Shi et al., 2006). Regardless of ecosystem types, there is a significant positive relationship between net ecosystem carbon uptake and temperature or precipitation among various ecosystems such as forest, grassland and cropland (Yu et al., 2006a). This suggests that temperature and moisture are the key factors controlling the pattern of ecosystem productivity on large spatial scales.

3.2.1.3. Soil carbon storage. Globally, soil carbon (C) is the largest terrestrial $\mathrm{C}$ pool and is an active participant in short-term net $\mathrm{CO}_{2}$ fluxes (Eswaran et al., 2000; Mielnick et al., 2005). In order to estimate $C$ storage and fluxes in terrestrial ecosystems, both organic and inorganic pools of the soil need to be considered. (i) Soil organic carbon storage: soil organic carbon (SOC) is not only an important component of the soils but also the most important ecological factor in global biogeochemical cycle. Wang et al. (2001) examined soil physio-chemical properties of China's terrestrial ecosystems based on the 2473 soil profiles from the second national soil survey over the area of $877.63 \times 10^{6} \mathrm{hm}^{2}$. Their estimate shows that the total amount of SOC is about $92.42 \mathrm{Pg} \mathrm{C}$ and soil carbon density is about $10.53 \mathrm{~kg} \mathrm{C} \mathrm{m}^{-2}$. SOC storage increases with latitude in eastern China and decreases with longitude in northern China. Large SOC variability is found along the transitional zone from one ecosystem to another, with great variation in carbon storage exists. Moreover, there is an increasing tendency of carbon density with decrease of latitude in western China. Soil carbon cycle is of great significance to global change, but presents substantial spatial variations across the country. Because of the heterogeneity in soil structure, large uncertainties remain in the estimate of soil carbon pools in China. It is necessary to further resolve soil respiration and organic matter conversion and other questions by developing uniform and normal methods of measurement and sampling. (ii) Soil inorganic carbon (SIC) storage: soils with pedogenic carbonate cover about $30 \%$ 
$\left(3.44 \times 10^{6} \mathrm{~km}^{2}\right)$ of land area in China, mainly in arid and semi-arid regions in the Northwest China. Based on the second national soil survey data (1979-1992), Mi et al. (2008) estimated total SIC stock at different soil incremental layers in China, and characterized its spatial distribution and its relation with climate, organic carbon distribution and land cover/vegetation type. Total SIC storage in China is $53.3 \pm 6.3 \mathrm{Pg} \mathrm{C}\left(1 \mathrm{Pg}=10^{15} \mathrm{~g}\right)$ to the depth up to $2 \mathrm{~m}$. In contrast with SOC storage, which is the highest when annual precipitation ranges from 500 to $800 \mathrm{~mm}$, SIC storage is the largest where annual precipitation is lower than $400 \mathrm{~mm}$. The amount and vertical distribution of SIC is related to climate and land cover type. SIC content in each incremental horizon is positively related with mean annual temperature and negatively related with mean annual precipitation. The magnitude of SIC content varies along land cover types in such order: desert, grassland > shrubland, cropland $>$ marsh, forest, meadow. SIC density generally increases with depth in all ecosystem types with the exceptions of deserts and marshes where it peaks in intermediate layers $(0.1-0.3 \mathrm{~m}$ for the desert and $0.3-0.5 \mathrm{~m}$ for the marshes). As an important player in soil carbon cycle, SIC dynamics, especially the mechanisms for SIC accumulation or loss, the exchange between SIC and atmosphere and its responses to climate and land use change, require an advanced exploration in global carbon cycle study.

\subsubsection{Ecosystem structure and functions}

3.2.2.1. Croplands. There is about 1.33 billion ha of cropland in China. The major research on agricultural ecosystems at the CERN field stations focuses on evolution of black soils in northeastern China, $\mathrm{C}$ and $\mathrm{N}$ cycles and their environmental impacts, water movement within soil-plant-atmosphere continuum (SPAC), allelopathy in plants and its role in eco-prevention against weeds, eco-chemical performance of chemical fertilizers, pesticide pollution and biological restoration of polluted croplands. Processbased model is an effective measure for probing the spatial and temporal variance of large scale carbon emission in that it includes detailed biogeochemical processes and is capable of explaining process stability, and addressing the natural and artificial control and feed back loops (Chakraborty et al., 2006). Simulation of the CENTURY model shows that carbon is released from the black soils after cultivation, and it reaches carbon saturation around 40 years later, which along with future climate change (especially the increase of precipitation) and elevated $\mathrm{CO}_{2}$ concentration, would increase organic content of the black soil (Yu et al., 2006a). For example, Han et al. (2005) used a carbon and nitrogen biogeochemical cycle model (DNDC) to estimate soil carbon sequestration potential (SCSP) of croplands in China. They found that a spatially large variations of SCSP among provinces due to differences in agricultural practices and the agricultural soils would be a carbon source for atmospheric $\mathrm{CO}_{2}$ unless conservation-tillage practices or other measures or improved management such as residual return, water-saving irrigation, no-tillage and fertilizer application were adopted (Han et al., 2005). Allelopathy, the suppression phenomenon of neighboring plant growth by the release of toxic compounds (allelochemicals) from living or dead plants, can play an important role in natural and managed ecosystems (Fitter, 2003). Allelopathy has been used to reduce herbicide use for weed control in crop fields.

3.2.2.2. Forests. China's forest is about 175 million ha and covers about $18.21 \%$ of the country's land area. China tops planted forests in the world and accounts for $26 \%$ of the world's total artificial forest area. Ecosystem structure, processes and functions and their responses to human activities and global change have been studied at different forest stations of CERN in terms of $\mathrm{C}, \mathrm{N}, \mathrm{H}_{2} \mathrm{O}$ cycles and their interactions, water resource conservation, nutrient balance, energy flow, species competition, seed bank, relationship between biodiversity and ecosystem productivity, and greenhouse gas uptake and emissions. Based on the long-term monitoring and measurements, many research highlights and important results have been derived and published in related journals, home and abroad. For example, based on analysis of 25 -year long soil organic carbon data observed in old-growth forests at the Dinghushan Station, Zhou et al. (2006) found that the soils in the top $20-\mathrm{cm}$ soil layer in the preserved old-growth forests in southern China accumulated atmospheric carbon at an unexpectedly high rate from 1979 to 2003. They also found that the mean bulk density of the top $20-\mathrm{cm}$ soil layer decreased significantly over the study period. This result challenges the prevailing belief that old-growth forests are carbon neutral or even net emitters of $\mathrm{CO}_{2}$. Although the mechanisms underlying this high SOC increase in the old-growth forests are not yet clear at present and deserve further study, their study does suggest that the belowground carbon cycle in oldgrowth forests is important in addressing global warming and that protecting those forests might be as important as planting new trees in offsetting atmospheric $\mathrm{CO}_{2}$ increase. Estimates from eddy covariance measurements, biomass inventory statistics and modeling work show that the 150-year-old forests in northeastern China (Changbaishan) also present a strong sink strength of 256$278 \mathrm{~g} \mathrm{C} \mathrm{m}^{2}$ per year (Yu et al., 2008).

3.2.2.3. Grasslands. Grasslands are the largest biome in China, occupying $41 \%$ of its terrestrial surface. The global climate change, such as atmospheric $\mathrm{CO}_{2}$ enrichment, climatic warming, increased variability in rainfall, can greatly affect key ecological processes and alter the structure and functions of grasslands. Many efforts have been made to probe the biogeochemistry, ecophysiology, vegetation structure and succession, biodiversity and ecosystem stability, biological evolution and adaptation, bio-physiology of clone plants, the responses to global changes and human disturbances of the typical temperate steppe and alpine meadow grasslands vastly distributed in Inner Mongolia and Tibet Plateau, respectively. Many scientific results have been obtained from the long-term monitoring and research. For example, based on the 24year vegetation investigation into a steppe ecosystem in Inner Mongolia, Bai et al. (2004) examined the ecosystem stability and compensatory effects of the steppe. They found that January-July precipitation is the primary climatic factor causing fluctuations in community biomass production, ecosystem stability increases progressively along the hierarchy of organizational levels from species to functional group then to whole community, and the community-level stability appears to be associated with compensatory interactions among major components at both species and functional group levels. From a hierarchical perspective, these results corroborate some previous findings of the compensatory effect. Besides, this study provides new insights for better management and restoration of the rapidly degrading grassland in Inner Mongolia. For restoring the vast areas of degraded grasslands in Inner Mongolia, it is important to establish and maintain grassland communities with a high diversity of dominant species and functional groups, so that compensatory mechanisms can enhance long-term ecosystem productivity and stability in response to climatic change (Bai et al., 2004). A recent study conducted in an Inner Mongolia Steppe confirms that plants can emit methane, a potent greenhouse gas, and that the methanemaking ability varies among types of plants (Wang et al., 2008).

3.2.2.4. Deserts. In China, semi-arid and arid areas cover almost half of the total land area, extending from northeast, north and northwest of China and some part of Qinghai-Tibet Plateau. Deserts are widely distributed in the semi-arid and arid areas, and account for about $28 \%$ of the land area of China. The research work 
conducted at the CERN stations in the arid and semi-arid areas focuses on survival adaptation strategies of plants under harsh environments, causes of desertification, mechanisms of ecological restoration (especially the role of biological crust), the relationship between clonal plants and species diversity in desert habitats, and ecosystem stability and sustainability. A recent study on soil $\mathrm{CO}_{2}$ absorption capacity of a desert ecosystem in western China suggests that alkaline soils can take up $\mathrm{CO}_{2}$ by an inorganic, nonbiological process, a phenomenon likely to have significant implications for the global carbon budget accounting (Xie et al., 2009).

3.2.2.5. Aquatic systems. The CERN research work on aquatic ecosystems touches mainly on lake eutrophication, functional restoration of eutrophicatified lakes, ecological processes and functioning of wetlands, coastal mangrove swamps, and coral reefs, population and community biology of phytoplankton, and food chains and their dynamics in shallow waters (lakes). A long hold rule of thumb ( $\mathrm{N}: \mathrm{P}$ rule) shows that bloom-forming cyanobacteria tends to dominate in lakes where the mass ratio of total nitrogen (N) to total phosphorus (P) is less than 29 and the proportion of cyanobacteria as a fraction of the total algal biomass will decrease with the N:P ratio exceeding 29 (Smith, 1983). Disputes remain, however, about the impact of $\mathrm{N}: \mathrm{P}$ ratio on phytoplankton populations (Reynolds, 1998). A study conducted at an enclosure experiment in the shallow, subtropical Donghu Lake in south China concluded that the $\mathrm{N}: \mathrm{P}$ rule is likely inapplicable to highly eutrophic systems, and cyanobacterial blooms as a key biological mechanisms drives the seasonal changes in the internal loading of phosphorus in shallow lakes (Xie et al., 2003).

\subsubsection{Ecosystem restoration and management}

Environmental stress affects human civilization mainly from two aspects: direct energy consumption and primary productivity degradation by human. It is shown that the available renewable energy resources can ensure not more than one-tenth of the modern energy consumption rate (Makarieva et al., 2008). Without curbing anthropogenic pressure on the ecosystems, the degradation of ecosystem and environment will be impossible to mitigated. China is a nation with a large population and low per-capita natural resources. The economy growth has been at a rate close to $10 \%$ over the past 30 years from 1978 . However, with the growth of both economy and population, China is now in a position at which the shortage of resources, and the environmental pressures (Fu, 2008), especially climate change, among others, are becoming a critical bottle-neck issue in its sustainable development. In some cases, the economy growth has brought severe impacts to natural and artificial ecosystems. Therefore, restoring disturbed ecosystems is a really big challenge for the governments in national and provincial levels. Through the demonstration experiments in the CERN field stations, some practical techniques and know-hows for restoration and rehabilitation of degraded ecosystems have been developed and then extrapolated to the locals. The efforts have been made to improve low yield croplands in the North China Plain, soil and water conservation in the Loess Plateau, re-vegetation of hilly regions in southern China, rehabilitation of eutroficatified lakes, protection and recovery of natural vegetation in ecologically fragile areas such as Karst systems, desert oases, ecotones, and permafrost, and restoration of desertified areas in north China. For example, the water-saving irrigation system, wind-break plantation, inter-cropping and alternative cropping systems are adopted in the arid and semiarid areas in China to increase or stabilize crop yields and improve land use gains. Fencing the steppe against grazing, adoption of rotational or conditional grazing, establishment of artificial vegetation of native species are proved to be effective measures to restore degraded grassland ecosystems. In addition, planting of wheat-straw sand arrestor (square straw checkerboard of about $1 \mathrm{~m} \times 1 \mathrm{~m}$ ) on deserts or sand dunes is helpful to vegetation recovery and also a powerful tool to protect the railways that pass through the deserts (Yang and Zou, 2000). In addition, assessments of ecosystem services have been conducted to provide sciencebased ecological information for sustainable ecosystem management and mitigation of climate change.

\subsection{Data management}

Since its establishment in 1988, CERN has collected a lot of monitoring and observation data through its field research stations and established a database at its Synthesis Research Center. In order to effectively manage the data and provide better service for scientists and researchers, many efforts have been made to standardize the long-term monitoring technique among all the CERN stations according to the ecological types of crop, forest, grassland, water, desert, swamp (marsh). Standardized techniques and methods for the collection, transfer, archiving, analysis and publication of data were applied to all the stations of CERN. The Standard of CERN's Long-term Monitoring Data has been published.

From 2001 to 2005, the Synthesis Research Center has, for the first time, achieved scientific management of long-term monitoring data from the 40 field stations. A three-tier (i.e. the field stations, sub-center, and synthesis center) data management system and an on-line information dissemination platform have been developed for the data managers to manage their own database at the field station, sub-center and synthesis center levels. Currently, a series of datasets are available for the public users. These datasets include: (i) the long-term monitoring dataset of hydrological, pedological, meteorological, and biological features and processes at each station; (ii) geophysical and geomorphologic dataset of each ecological field station; (iii) the carbon budget and flux dataset of typical terrestrial ecosystems; (iv) land resources dataset, and (v) $1 \mathrm{~km} \times 1 \mathrm{~km}$ meteorological grid dataset of China, among others. Up till now, CERN has published the Spatial Information Atlas of CERN Field Stations and the Statistical Dataset for Water, Soil, Atmosphere and Biology of CERN (1998-2001). Some of those data (including the station historical records and background description (nature, social, economy and ecological situation)) are also accessible on CERN website (http://www.cern.ac.cn). The CERN database provides a valuable resource for the broader scientific community to conduct the cross-site and synthetic research on ecological processes and global change issues over various ecosystems across China.

\section{Perspectives of CERN development}

\subsection{CERN strategic planning to 2020}

The Scientific Committee of CERN prepared the Strategic Plan of CERN in December 2006. After that, relevant experts were brought together to conduct thematic studies on various ecosystems, i.e. cropland, forest, grassland, desert, aquatic ecosystems, as well as on network-based and synthesis research, by focusing on the current status of CERN and its goal, the needs of national and local governments on socio-economic development, the frontiers of different disciplines, and the scientific objectives, and by referring to the detailed plans of the ecological stations, sub-centers and synthesis center of CERN. The overall strategic plan was finalized in October 2008. More than 100 scientists of CERN have been directly engaged in the process, and more than 300 experts and officials have provided their valuable inputs to the strategic plan. 
The strategic plan is designed to highlight the key directions of the medium and long-term development of CERN, promote the capacity-building in monitoring, research and demonstration, and proposes the overall goal and objectives at different stages for CERN by 2020, as well as the five measures to support the implementation of the strategic plan. The overall goal of CERN is defined as: by 2020, a series of original findings on fundamental ecological study be achieved, with breakthrough made in some areas, producing significant impact in international community; some key ecological issues on ecology development, environmental protection and sustainable agricultural development that are critical for the country be resolved; CERN develop into a national science and technological innovation base and long-term ecological research facility in Asia in terms of long-term ecosystem monitoring, research and demonstration.

\subsection{Regional and network monitoring}

Under the context of global change, defining the changes of various ecosystems in structure and function, and defining of energy and matters flow can only be made possible with the longterm dynamic monitoring on the representative ecosystems. The ecological stations of CERN located in each representative ecoregion should, first of all, serve as a long-term monitoring site. Due to the complexity of ecological processes, the ecosystems may exhibit different features at various temporal scales. The previous studies have indicated that the findings over several decades may be quite different from those of short term (Tilman, 1989). It is, therefore, necessary to carry on the established monitoring indicator systems and monitoring plans on a long-term basis.

At the same time, all the ecological stations of CERN (or the ecological-station clusters that can work as a network within a region) should focus on some key ecologically scientific issues to conduct network-based research and specific monitoring. Each sub-center needs to enhance data integration at its own discipline, whereas the synthesis center is required to conduct further data mining and consolidation at national, regional or global scales by integrating the transect-based studies to generate some major research findings and provide scientific information for the national policy-making.

In the future, the major task of capacity-building for CERN is to improve its capacity in integrated monitoring, i.e. the threedimensional monitoring, based on conventional monitoring. Great efforts should be made to learn from the best international practices, leverage the latest findings in various fields such as remote sensing, aerospace, information technology and life science, and take full advantage of the individual strength of the ecological stations of CERN distributed in each representative region towards an ultimate goal to gradually expand the monitoring from a single site to the landscape, national, regional or even global scales. It is also necessary to resolve the key technologies in information sharing and data management, based on the sound indicators system and technical protocol of long-term ecological monitoring and data sharing mechanism; to develop new technologies and tools for the monitoring, simulation and integrated data analysis of the key ecological processes such as carbon, nitrogen and water cycling; to develop methodologies on eco-informatics and key technologies of remote data transfer and integrated analysis; to conduct ground-based, network-scaled monitoring, and collect spatial ecological information.

Dynamic analysis of monitoring data and the public service is one of the most important means to enhance the social influence and vitality of CERN. All the member organizations of CERN, based on its monitoring, need to update the central and local governments with the latest information on ecosystem changes to provide support for their policy-making, provide publicity material to improve the public awareness on environmental protection, and provide information services to promote the national and local socioeconomic development and environmental conditions in China.

\subsection{Focusing on key scientific issues}

The power of the network approach of the LTER program rests in the ability to compare similar processes (e.g. primary production or decomposition of organic matter) under different ecological conditions. As a result, LTER scientists should be able to understand how fundamental ecological processes operate at different rates and in different ways under different environmental conditions. The objectives of scientific research for CERN are defined as: to reveal the patterns of ecosystem structure, function and process changes driven by global change and human activities, and to explore the management approaches on ecosystem structure, pattern and process, by integrating the long-term monitoring and experiment on various ecosystems in different regions in China, with the indoors simulation, remote sensing and modeling at various scales, with an ultimate goal to provide reliable dynamic monitoring data, solid scientific basis and applicable technical tools on a breadth of topics, such as biodiversity conservation, ecosystem management, food production, wise use of natural resources, environmental protection and global change. Specifically, synthesis research will be undertaken in the following six core thematic areas.

\subsubsection{Coupling carbon, nitrogen and water cycling processes}

By focusing on the carbon, nitrogen and water cycling in terrestrial ecosystems, we intend to conduct network-based monitoring on carbon, nitrogen and water fluxes in terrestrial ecosystems and controlled experiments on the cycling processes. We will enhance studies on the impact of human activities onto the carbon, nitrogen and water cycling, develop advanced technologies and tools on monitoring, modeling, inverting with remote sensing, and tracing with isotope these cycling processes, and conduct synthesis studies on the mechanism of biogeochemical cycling of ecosystem's life factors, as well as the control mechanism of environmental and biological factors onto these cycling. We will also assess the spatio-temporal patterns of these cycling in the key areas in China and its feedback onto climate change, and explore the ecological approaches to control and optimize the management of these cycling processes.

By 2020, the key scientific issues for CERN in this thematic area will be: (i) carbon, nitrogen and water cycles and their coupling in the terrestrial ecosystems; (ii) nitrogen and phosphorous cycles of aquatic ecosystems; (iii) regional carbon sink dynamics and carbon management.

\subsubsection{Response and adaptation of ecosystems to global climate change}

At the site, transect and regional scales, studies will be undertaken on the response, adaptability and feedback of ecosystems in ecologically sensitive areas, ecologically fragile areas and eco-regions. Focus will be made on the patterns of changes for the interactions among geosphere-biosphere-atmosphere under global climate change, ecosystem functions, processes and spatial distribution, as well as the predicting methods. Investigations will be made on the response and adaptation of soil processes of typical forest, grassland, cropland and wetland ecosystems onto global climate change, as well as on the role of coastal ecosystems in global carbon cycle. Observation and research network on the climate change adaptability will be further developed to explore the approaches and tools for ecosystem management of mitigating and adapting to the global climate change.

By 2020, the key scientific issues for CERN in this thematic area will be as follows: (i) the impact of main factors for global climate 
change onto the key ecosystem processes; (ii) the response and adaptability of ecosystems in ecologically sensitive areas, ecologically fragile areas and eco-regions onto global climate change; (iii) the response and adaptability of ecosystems onto extreme events and natural disasters.

\subsubsection{Biodiversity conservation and biological resources exploitation}

Large-scaled controlled experiments will be employed to investigate the role of biodiversity in maintaining ecosystem functions, to explore the mechanism of maintaining biodiversity, as well as the interactions between the structural and functional changes of biodiversity and ecosystems, to analyze the interactions among species diversity, function diversity, ecosystems productivity, stability and sustainability, and to understand the mechanism of biological diversity and complexity and community structure in affecting and controlling the ecosystem functions. As a sine qua non for biodiversity research, species dynamics need an in-depth exploration, e.g. the species spreading mechanism (Morozov et al., 2008). In biodiversity management, biodiversity measures such as biodiversity index, the Kullback information measure and exergy, etc. can been used to check and trace (and, potentially, to predict) changes structure (Petrovskaya et al., 2006). We will study the ecological mechanism of species evolution in some key areas, develop the technologies in conserving the germ plasma resources and in exploiting the biological resources and bio-energy plants, and assess their sustainability and their ecological impacts.

By 2020, the key scientific issues for CERN in this thematic area will be: (i) the impact of biodiversity changes onto the ecosystem structures and functions; (ii) the ecological methodology of sustainably using biological resources.

\subsubsection{Ecosystem restoration and sustainability}

Based on the full understanding of global and regional ecological changes, we intend to assess the structural and functional changes of major ecosystems in China under the combined effects of human activities and climate change. We will study the degradation processes and restoration mechanism of various ecosystems in different areas in China, and develop key technologies and demonstration models on restoration. We will, based on the principles of ecosystem ecology, define technological action plan, ecological approach and integrated tools on restoring the degraded ecosystems, and assess the benefits of key ecological programs and projects. To address the pressures to ecological conditions due to the population growth and rapid economic development in China, we will also conduct synthesis research on the interactions between regional ecosystems and socio-economic systems to provide science-based information to the policymaking on regional resources use, eco-environmental protection and socio-economic development in the country.

By 2020, the key scientific issues for CERN in this thematic area will be: (i) the approaches and mechanism on restoring the structures and functions of degraded ecosystems; (ii) key technologies and optimized management model for ecological restoration in the ecologically fragile areas; (iii) approaches and criteria of assessing the benefits of key ecological programs and projects in China.

\subsubsection{The impact of human activities on ecosystem structures and functions}

Under this thematic area, we will explore the impact of land use change, urbanization, environmental pollution and other major human activities onto ecosystem changes, assess the patterns and the environmental effects of ecosystem structural and functional changes under human activities, as well as the role and the mechanism of regular human activities and ecosystem manage- ment in ecosystem restoration, and evaluate the loading, transfer, transformation and environmental risks of environmental pollutants in ecosystems.

By 2020, the key scientific issues for CERN in this thematic area will be: (i) the impact of land use change onto ecosystem structures and functions; (ii) assessment on the loading, transfer, transformation and environmental risks of pollutants in ecosystems; (iii) the effect of atmospheric pollution onto regional ecosystems; (iv) the impact of urbanization drive onto regional ecosystems.

\subsubsection{Ecological monitoring, modeling and eco-informatics application}

Studies will be undertaken on the indicators, protocols and data sharing mechanism of long-term ecosystem monitoring. Key technologies on information sharing and data management, new approaches and tools in monitoring the ecosystem changes, carbon, nitrogen and water cycling processes, as well as new theories and methodologies on ecosystem modeling, integrated data analysis and scaling, will be further developed. In addition, we will promote the theories of eco-informatics, develop key technologies on data collection-remote transfer-integrated research in ecosystem monitoring and experiments, explore the theories and tools of eco-information spatialization based on dynamic monitoring via ground network, and develop basic gridbased spatial database and information system.

By 2020, the key scientific issues for CERN in this thematic area will be: (i) site-based, real-time and dynamic monitoring and technical integration of ecosystem changes; (ii) quality control tools of eco-information and key technologies in data management; (iii) the application of information technology in ecosystem research and management.

\section{Conclusions}

A fundamental property of site-based research is that the knowledge base and the comprehensive understanding increase over time. Not only are dynamics more apparent over time, but also the breadth and integration of the knowledge increases (Hobbie et al., 2003). The CERN sites cover almost all typical ecosystems in China: cropland, forest, grassland, desert, marshes, lakes, bays and urban ecosystem, etc. Its unique features are the emphasis on understanding long-term patterns and processes of ecological systems, combination of the cross-site or comparison research and the voluntary site-based exploration, and the data sharing both with domestic institutions and international networks at different levels. From 1993, a cooperating network of international LTER (i.e. ILTER), in which CERN acts as an active sponsor and member, has been created with members developed from 14 in 1993 to 38 in 2007 spread all over five continents. Through 20 year's development from 1988, CERN plays a more and more important role in long-term ecological monitoring, research and application in the world.

\section{Acknowledgments}

This paper is for 20th anniversary of Chinese Ecosystem Research Network establishment. We thank the contribution of all scientists and staffs to CERN during past 20 years. The paper was supported by the National Basic Research Program of China (No. 2009CB421100) and Chinese Academy of Sciences (No. KZCX2-YW-Q1-15).

\section{References}

Bai, Y.F., Han, X.G., Wu, J.G., Chen, Z.Z., Li, L.H., 2004. Ecosystem stability and compensatory effects in the Inner Mongolia grassland. Nature 431 (7005), $181-184$. 
Cao, M.K., Pringce, S.D., Li, K.R., Tao, B., Small, J., Shao, X.M., 2003. Response of terrestrial carbon uptake to climate interannual variability in China. Global Change Biol. 9 (4), 536-546.

Chakraborty, A., Bhattacharya, D.K., Li, B.L., 2006. Spatiotemporal dynamics of methane emission from rice fields at global scale. Ecol. Complex. 3 (3), 231 240.

Eswaran, H., Reich, P.F., Kimble, J.M., 2000. Global carbon stocks. In: Lal, R., Kimble J.M., Eswaran, H., Stewart, B.A. (Eds.), Global Climate Change and Pedogenic Carbonates. CRC Press, Boca Raton, pp. 15-25.

Fitter, A., 2003. Making allelopathy respectable. Science 301 (5638), 1337-1338.

Fu, B.J., 2008. Blue skies for China. Science 321, 611.

Fu, Y.L., Yu, G.R., Wang, Y.F., Li, Z.Q., Hao, Y.B., 2006. Effect of water stress on ecosystem photosynthesis and respiration of a Leymus chinensis steppe in Inner Mongolia. Sci. China Earth Sci. 49 (Suppl. II), 196-206.

Han, B., Wang, X.K., OuYang, Z.Y., 2005. Saturation levels and carbon sequestration potentials of soil carbon pools in farm land ecosystems of China. Rural EcoEnviron. 21 (4), 6-11 (in Chinese).

Hobbie, J.E., Carpenter, S.R., Grimm, N.B., Gosz, J.R., Seastedt, T.R., 2003. The US long term ecological research program. Bioscience 53 (1), 21-32.

Hu, B., Wang, Y.S., Liu, G.R., 2007a. Ultraviolet radiation spatio-temporal characteristics derived from the ground-based measurements taken in China. Atmos. Environ. 41 (27), 5707-5718.

Hu, B., Wang, Y.S., Liu, G.R., 2007b. The spatio-temporal characteristics of photosynthetically active radiation in China. J. Geophys. Res. 112 (D14), D14106, doi:10.1029/2006JD007965.

Makarieva, A.M., Gorshkov, V.C., Li, B.L., 2008. Energy budget of the biosphere and civilization: rethinking environmental security of global renewable and nonrenewable resources. Ecol. Complex. 5 (4), 281-288.

Mi, N., Wang, S.Q., Liu, J.Y., Yu, G.R., Zhang, W.J., Jobbágy, E., 2008. Soil inorganic carbon storage pattern in China. Global Change Biol. 14 (10), 2380-2387.

Mielnick, P., Dugas, W.A., Mitchell, K., Havstad, K., 2005. Long-term measurements of $\mathrm{CO}_{2}$ flux and evapotranspiration in a Chihuahuan desert grassland. J. Arid Environ. 60 (3), 423-436.

Morozov, A., Ruan, S.G., Li, B.L., 2008. Patterns of patchy spread in multi-species reaction-diffusion models. Ecol. Complex. 5 (4), 313-328.

Petrovskaya, N., Petrovskii, S., Li, B.L., 2006. Biodiversity measures revisited. Ecol. Complex. 3 (1), 13-22.

Reynolds, C.S., 1998. What factors influence the species composition of phytoplankton in lakes of different trophic status? Hydrobiologia 369-370, 11-26.
Shi, P.L., Sun, X.M., Xu, L.L., Zhang, X.Z., He, Y.T., Zhang, D.Q., Yu, G.R., 2006. Net ecosystem $\mathrm{CO}_{2}$ exchange and controlling factors in a steppe-Kobresia meadow on the Tibetan Plateau. Sci. China Earth Sci. 49 (Suppl. II), 207-218.

Smith, V.H., 1983. Low nitrogen to phosphorus ratios favor dominance by bluegreen algae in lake phytoplankton. Science 221 (4611), 669-671.

Tilman, D., 1989. Ecological experimentation: strengths and conceptual problems. In: Likens, G.E. (Ed.), Long-Term Studies in Ecology. Springer-Verlag, New York, pp. 136-157.

Wang, S.Q., Zhou, C.H., Li, K.R., Zhu, S.L., Huang, F.H., 2001. Study on spatial distribution character analysis of the soil organic carbon reservoir in China. J. Geogr. Sci. 11 (1), 3-13.

Wang, Z.P., Han, X.G., Wang, G.G., Song, Y., Gulledge, J., 2008. Aerobic methane emission from plants in the Inner Mongolia Steppe. Environ. Sci. Technol. 42 (1), 62-68.

Xie, J.X., Li, Y., Zhai, C.X., Li, C.H., Lan, Z.D., 2009. CO 2 absorption by alkaline soils and its implication to the global carbon cycle. Environ. Geol. 56 (5), 953-961.

Xie, L.Q., Xie, P., Li, S.X., Tang, H.J., Liu, H., 2003. The low TN:TP ratio, a cause or a result of microcystis blooms? Water Res. 37 (9) 2973-2080.

Xin, J.Y, Wang, Y.S., Li, Z.Q., Wang, P.C., Hao, W.M., Wang, S.G., Nordgren, B.L., Liu, G.R., Wang, L.L., Wen, T.X., Sun, Y., Hu, B., 2007. Aerosol optical depth (AOD) and Ångström exponent of aerosols observed by the Chinese Sun Hazemeter Network from August 2004 to September 2005. J. Geophys. Res. Atmos. 112, D05203, doi:10.1029/2006JD007075.

Yang, J.P., Zou, L.J., 2000. Study on the status of desertification and its control in China. J. Arid Land Resour. Environ. 14 (3), 15-23 (in Chinese).

Yu, G.R., Fang, H.J., Gao, L.P., Zhang, W.J., 2006a. Soil organic carbon budget and fertility variation of black soils in Northeast China. Ecol. Res. 21 (6), 855-867.

Yu, G.R., Fu, Y.L., Sun, X.M., Wen, X.F., Zhang, L.M., 2006b. Recent progress and future directions of China FLUX. Sci. China Earth Sci. 49 (Suppl. II), 1-23.

Yu, G.R., Wen, X.F., Tanner, B.D., Sun, X.M., Lee, X.H., Chen, J.Y., 2006c. Overview of China FLUX and evaluation of its eddy covariance measurement. Agric. Forest Meteorol. 137 (3-4), 125-137.

Yu, G.R., Zhang, L.M., Sun, X.M., Fu, Y.L., Wen, X.F., Wang, Q.F., Li, S.G., Ren, C.Y., Song X., Liu, Y.F., Han, S.J., Yan, J.H., 2008. Environmental controls over carbon exchange of three forest ecosystems in eastern China. Global Change Biol. 14 (11), 2555-2571.

Zhao, L., Li, Y.N., Zhao, X.Q., Xu, S.X., Tang, Y.H., Yu, G.R., Gu, S., Du, M.Y., Wang, Q.X., 2005. Comparative study of the net exchange of $\mathrm{CO}_{2}$ in 3 types of vegetation ecosystems on the Qinghai-Tibetan Plateau. Chin. Sci. Bull. 50 (16), 1767-1774.

Zhou, G.Y., Liu, S.G., Li, Z.A., Zhang, D.Q., Tang, X.L., Zhou, C.Y., Yan, J.H., Mo, J.M., 2006. Old-growth forests can accumulate carbon in soils. Science 314 (5804), 1417. 